\title{
Zona pellucida protein ZP2 is expressed in the oocyte of Japanese quail (Coturnix japonica)
}

\author{
Mihoko Kinoshita, Daniela Rodler ${ }^{1}$, Kenichi Sugiura, Kayoko Matsushima, Norio Kansaku ${ }^{2}$, \\ Kenichi Tahara ${ }^{3}$, Akira Tsukada ${ }^{3}$, Hiroko Ono ${ }^{3}$, Takashi Yoshimura ${ }^{3}$, Norio Yoshizaki ${ }^{4}$, \\ Ryota Tanaka ${ }^{5}$, Tetsuya Kohsaka and Tomohiro Sasanami \\ Department of Applied Biological Chemistry, Faculty of Agriculture, Shizuoka University, 836 Ohya, Shizuoka \\ 422-8529, Japan, 'Institute of Veterinary Anatomy II, University of Munich, Veterinaerstrasse 13, 80539 Munich, \\ Germany, ${ }^{2}$ Laboratory of Animal Genetics and Breeding, Azabu University, Fuchinobe, Sagamihara 229-8501, Japan, \\ ${ }^{3}$ Graduate School of Bioagricultural Sciences, Nagoya University, Furo-cho, Chikusa-ku, Nagoya 464-8601, Japan, \\ ${ }^{4}$ Department of Agricultural Science, Gifu University, Gifu 501-1193, Japan and ${ }^{5}$ Biosafety Research Center, Foods, \\ Drugs, and Pesticides (An-Pyo Center), Iwata 437-1213, Japan
}

Correspondence should be addressed to T Sasanami; Email: atsasan@agr.shizuoka.ac.jp

\begin{abstract}
The avian perivitelline layer (PL), a vestment homologous to the zona pellucida (ZP) of mammalian oocytes, is composed of at least three glycoproteins. Our previous studies have demonstrated that the matrix's components, ZP3 and ZPD, are synthesized in ovarian granulosa cells. Another component, ZP1, is synthesized in the liver and is transported to the ovary by blood circulation. In this study, we report the isolation of cDNA encoding quail ZP2 and its expression in the female bird. By RNase protection assay and in situ hybridization, we demonstrate that ZP2 transcripts are restricted to the oocytes of small white follicles (SWF). The expression level of ZP2 decreased dramatically during follicular development, and the highest expression was observed in the SWF. Western blot and immunohistochemical analyses using the specific antibody against ZP2 indicate that the $80 \mathrm{kDa}$ protein is the authentic ZP2, and the immunoreactive ZP2 protein is also present in the oocytes. Moreover, ultrastructural analysis demonstrated that the immunoreactive ZP2 localizes to the zona radiata, the perivitelline space, and the oocyte cytoplasm in the SWF. By means of western blot analysis and immunofluorescence microscopy, we detected a possible interaction of the recombinant ZP2 with ZP3 and that this interaction might lead to the formation of amorphous structure on the cell surface. These results demonstrate for the first time that the avian ZP gene is expressed in the oocyte, and that the ZP2 protein in the oocyte might play a role for the PL formation in the immature follicles of the ovary.

Reproduction (2010) 139 359-371
\end{abstract}

\section{Introduction}

The egg envelope is an extracellular matrix that surrounds the oocyte of vertebrate animals and plays essential roles in gamete recognition during the initial process of fertilization, including species-specific sperm-egg binding, induction of the acrosome reaction, and prevention of polyspermy (McLeskey et al. 1998). These egg envelopes are mainly constructed of glycoproteins belonging to different subclasses of the zona pellucida (ZP) gene family (Spargo \& Hope 2003, Conner et al. 2005, Smith et al. 2005). The components of this matrix include three or four glycoproteins (i.e., ZP1, ZP2, ZP3, and ZP4) in mammalian species (Lefievre et al. 2004, Hoodbhoy et al. 2005, Litscher \& Wassarman 2007, Ganguly et al. 2008, Izquierdo-Rico et al. 2009). In the cases of nonmammalian vertebrate such as amphibians (i.e. Xenopus laevis and Xenopus tropicalis), five ZP glycoproteins (ZP2, ZP3, ZP4, ZPD, and ZPAX) have been identified (Lindsay et al. 2003, Goudet et al. 2008). The ZP gene family proteins share a highly conserved amino acid sequence near the C-terminus called the ZP domain, consisting of about 260 amino acid residues with eight or ten conserved Cys residues (Bork \& Sander 1992).

The avian ovum is enveloped by multiple layers of different extracellular matrices, including an inner layer of vitelline membrane, a continuous membrane, and an outer layer of vitelline membrane (Bellairs et al. 1963). At the time of ovulation, the avian oocyte is surrounded by the inner layer of vitelline membrane, also referred to as the perivitelline layer (PL), which is a rough meshwork of thick filaments mainly composed of glycoproteins (Wyburn et al. 1965). PL is a homologue of the egg envelope in other vertebrates, the ZP in mammals, the vitelline membrane in amphibians, and the chorion in teleosts. Although the penetration of the PL by 
supernumerary spermatozoa is found regularly in birds, the $\mathrm{PL}$ behaves in a manner analogous to the $\mathrm{ZP}$ in mammalian species (Howarth 1990, Sasanami et al. 2007). During follicular development, because avian oocytes dramatically increase their size by the accumulation of egg yolk delivered from blood circulation (Wyburn et al. 1965), their egg envelope must extend quickly throughout the rapid growing period of the oocyte.

In avian species, three glycoproteins have been identified as the component of PL, ZP1, ZP3, and ZPD in both quail (Pan et al. 2001, Sasanami et al. 2003b, Sato et al. 2009) and chickens (Waclawek et al. 1998, Takeuchi et al. 1999, Bausek et al. 2000, Okumura et al. 2004). These glycoproteins coordinately assemble into the fibrous matrix on the surface of the oocyte (Sasanami et al. 2004), and one of its major components, ZP1, has the ability to induce the sperm acrosome reaction in Japanese quail (Sasanami et al. 2007).

It has been suggested that in mouse ZP the three glycoproteins, ZP1, ZP2 and ZP3, are organized into long filaments and that these filaments are comprised of the long chains of the ZP2/ZP3 heterodimer, which are interconnected by ZP1 with disulfide bonds giving rise to a threedimensional matrix (Greve \& Wassarman 1985). Among these glycoproteins, it has been suggested that ZP3 behaves as a primary sperm-binding ligand and that this relatively species-specific binding leads to the successful induction and completion of the sperm acrosome reaction (Wassarman \& Litscher 2008). In addition, the ZP2 protein has been proposed to play a role in secondary binding of the sperm that assists the weak association of the acrosome-reacted sperm to the egg during fertilization (Wassarman \& Litscher 2008). It has also been suggested that proteolytic cleavage of ZP2 after cortical reaction contributes to the blockade of polyspermy (Dean 2003).

It has been reported that the avian PL is comprised of two major glycoproteins, ZP1 and ZP3, because after the separation of the PL constituents by SDS-PAGE, only two major bands ( 175 and $35 \mathrm{kDa}$ in the quail and 183 and $32 \mathrm{kDa}$ in the chicken) identified as ZP1 and ZP3 respectively were detected with Coomassie brilliant blue (CBB) staining (Kido \& Doi 1988, Mori \& Masuda 1993). Thus, if other constituents are present in the $\mathrm{PL}$, including $Z P 2$, they might be present in lower amounts than in mammalian ZP. A recent analysis of chicken genome and expressed sequence tag (EST) sequence data has revealed that the $Z P 2$ gene is expressed in the ovary and that the cDNA encoding chicken ZP2 has been cloned (Hughes 2007, GenBank accession number: AB197938). However, whether or not the ZP2 proteins actually present in the ovary is not known, and the question of which cells express this gene is still unanswered. In the present study, we cloned quail $Z P 2 \mathrm{cDNA}$, and show that the $Z P 2$ gene is expressed in the oocytes of the small white follicles (SWF). Moreover, we also provide details about the localization of the ZP2 protein in the follicles as well as the expression pattern of the gene.

\section{Results \\ Cloning of quail ZP2}

The degenerate PCR and RACE procedures led to the isolation of the cDNA covering the open reading frame and UTRs of quail ZP2 (Fig. 1A). The sequences have been deposited in the GenBank database (accession number: AB295393). The amplified sequence of $Z P 2$ is 2196 nucleotides long and contains a single open reading frame. This sequence contains an ATG initiation codon and a stop codon (TAA) in positions at 1-3 and 2083-2085 respectively, and a polyadenylation signal (AATTAAA) is found in positions at 2107-2113.

The isolated cDNA encoded 694 amino acids with a theoretical molecular mass of $75.585 \mathrm{kDa}$, including a predicted 21-amino acid signal peptide (Fig. 1A). As with other ZP proteins, ZP2 contains a ZP domain $\left(\mathrm{Val}^{347}-\mathrm{Leu}^{613}\right)$ and a consensus furin cleavage site $\left(\right.$ Arg $^{615}-$ Ser $^{616}-$ Lys $^{617}-$ Arg $^{618}$ ) near the C terminus, indicating the possibility that the C-terminal region of the newly synthesized precursor protein could be proteolytically processed by furin-like protease. The molecular mass of the processed peptide (with no signal peptide and cleavage at $\mathrm{Arg}^{618}$ in the C-terminal region of ZP2 protein) was calculated to be $65.891 \mathrm{kDa}$. The sequences showed a high degree of hydrophobicity at the C-terminal region corresponding to the transmembrane domain between $\mathrm{Val}^{664}$ and $\mathrm{Leu}^{680}$, which was followed by a short cytoplasmic tail. Quail ZP2 was compared with ZP2 protein from domestic fowl (Fig. 1B). The quail ZP2 is closely related to its chicken counterpart and the amino acid sequence shows a high degree of homology $(84.6 \%)$. There are six putative $\mathrm{N}$-glycosylation sites in the translated protein, which are completely conserved with chicken homologue. Ten Cys residues were seen in the $\mathrm{ZP}$ domain of the quail $\mathrm{ZP2}$ and all of the Cys are completely conserved in the ZP domains of chicken and quail ZP2, suggesting that their three-dimensional structures are similar to each other. These common features suggest that our clone is an authentic member of ZP2.

\section{mRNA expression of ZP2 in quail}

To investigate the tissue distribution of $Z P 2$ transcripts, we analyzed the total RNA isolated from various tissues of laying quail using a gene-specific RNase protection assay. As shown in Fig. 2A, a single protected probe fragment was detected only in the samples prepared from SWF (lane 10, Fig. 2B). No detectable signals were seen in the RNA samples isolated from the other tissues tested. No such signal above the background was observed when the same sample was hybridized with sense probe, confirming the specificity of the hybridization (data not shown). It should be noted that the size of the protected fragment was smaller than that of the probe itself (lane 1) because the RNase treatment can 
A

- 48 TGGTGGTTGGGGCTGTTTGTGGGGGGCAGCAGCTCTGGCACTTTGAGG

1 ATGAGGCTGCTGCTGCTCCTCTTGGTTGGATTTTTGCTGTTCTTGGCCCCTGGTGCCTCAGGGCAATGGGATCTCTCAGAGAGCACGACCTGCCTGCAGGACAGGCTGGAGCTGGAGCTC

$\begin{array}{llllllllllllllllllllllllllllllllllllllllll}1 & M & R & L & L & L & L & L & L & V & G & F & L & L & F & L & A & P & G & A & S & G & Q & \text { W } & \text { D } & \text { L } & \text { S } & \text { E } & \text { S } & \text { T } & \text { T } & \text { C } & \text { L } & Q & \text { D } & \text { R } & \text { L } & \text { E } & \text { L } & \text { E } & \text { L }\end{array}$ 121 CCCACGGAGCTGGGCAATTACACGTGGCATGCGCGCGCGGTGGATGTGAGTGGGGAGGAGATGGCATCCTGTGAGCTCACTGTGGATTATGAGAAGCTGCTGCTCAGTGCCTTGTTGGTG

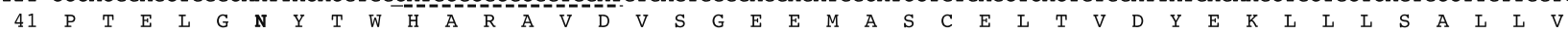
241 AACTGCACCAGCCTGGAGCACGGGCAGCACCAGCTGAGGCTGCTCCTGCTGCTCAATGGCACCGCGGGGGAGGAGAGGAACGTCACCTTCAGTGCCCGCTGCAGCGCTGCCCGCGGGGAT $\begin{array}{llllllllllllllllllllllllllllllllllllllllll}81 & \mathbf{N} & \text { C } & \text { T } & \text { S } & \text { L } & \text { E } & \text { H } & G & Q & \text { H } & Q & \text { L } & \text { R } & \text { L } & \text { L } & \text { L } & \text { L } & \text { L } & \text { N } & \text { G } & \text { T } & \text { A } & G & \text { E } & \text { E } & \text { R } & \text { N } & \text { V } & \text { T } & \text { F } & \text { S } & \text { A } & R & \text { C } & \text { S } & \text { A } & \text { A } & R & G & D\end{array}$ 361 GAAATCATCGCTCCTGTCTTTGTTGGTGCAACAAACTGCACAAAGGATTCCATGGCAGTTACTTTCCCAGGACCAAGCCTTGGCAATGAGCGCCCGGTTCAGGTGGCTGCGCTGCCCAGA $\begin{array}{lllllllllllllllllllllllllllllllllllllllllll}121 & \text { E } & \text { I } & \text { I } & \text { A } & \text { P } & \text { V } & \text { F } & \text { V } & \text { G } & \text { A } & \text { T } & \text { N } & \text { C } & \text { T } & \text { K } & \text { D } & \text { S } & \text { M } & \text { A } & \text { V } & \text { T } & \text { F } & \text { P } & \text { G } & \text { P } & \text { S } & \text { L } & \text { G } & \text { N } & \text { E } & \text { R } & \text { P } & V & O & V & A & A & \text { L } & P & R\end{array}$ 481 ACTCTGGTGATTGATGATGGAACCAGGGTGCACCAGCTGAGCCCTGGGGAAGCCTCGCAGCACGGCTACAGCTTTCAGGCTGACGGACACAGCCTGGTTCTCCAGGCAGCCTTCACTGCC $\begin{array}{llllllllllllllllllllllllllllllllllllllllll}161 & \text { T } & \text { L } & \text { V } & \text { I } & \text { D } & \text { D } & \text { G } & \text { T } & \text { R } & \text { V } & \text { H } & \text { Q } & \text { L } & \text { S } & \text { P } & \text { G } & \text { E } & \text { A } & \text { S } & \text { Q } & \text { H } & \text { G } & \text { Y } & \text { S } & \text { F } & \text { Q } & \text { A } & \text { D } & \text { G } & \text { H } & \text { S } & \text { L } & \text { V } & \text { L } & Q & \text { A } & \text { A } & \text { F } & \text { T } & \text { A }\end{array}$ 601 ACTGGAGTTGTCTCCTACCAGCATAACCACAAGGTGCTCTACACTGCGGCAGTGAAGCTCACGTATGGCCCTCCTGAACACAGGCTGACCATGGAGTCAAGAATGCTTTGTGCCCCAGGT $\begin{array}{llllllllllllllllllllllllllllllllllllllllll}201 & \text { T } & G & V & V & S & Y & O & \text { H } & \text { N } & \text { H } & \text { K } & \text { V } & \text { L } & \text { Y } & \text { T } & \text { A } & \text { A } & \text { V } & \text { K } & \text { L } & \text { T } & \text { Y } & \text { G } & \text { P } & \text { P } & \text { E } & \text { H } & \text { R } & \text { L } & \text { T } & \text { M } & \text { E } & \text { S } & \text { R } & M & \text { L } & \text { C } & \text { A } & \text { P } & G\end{array}$ 721 CCGGTGCTGTGTAACACAACACACATGACTGTGGCCGTCCCAGCCTTCCCAGGGACCCTCGTATCTGTGGCTGTGGAGGATGAGACCATCCCAATGGACCGGCTCCAGGACAACGGCATC $\begin{array}{llllllllllllllllllllllllllllllllllllllllll}241 & \text { P } & \text { V } & \text { L } & \text { C } & \text { N } & \text { T } & \text { T } & \text { H } & \text { M } & \text { T } & \text { V } & \text { A } & \text { V } & \text { P } & \text { A } & \text { F } & \text { P } & \text { G } & \text { T } & \text { L } & \text { V } & \text { S } & \text { V } & \text { A } & \text { V } & \text { E } & \text { D } & \text { E } & \text { T } & \text { I } & \text { P } & \text { M } & \text { D } & R & \text { L } & Q & \text { D } & N & G & I\end{array}$ 841 ACTCTCAGCACAGCACGAGGGGGGTGGAGCTGCACGTCAGCAGGGGGGTCCTGGAAGTCTGCACTACATGGGGAGAGCTGCCCAGGAGCTCGGTCCTACCTGCCCTCCTTGGAGCTGACT $\begin{array}{lllllllllllllllllllllllllllllllllllllllll}281 & T & \text { L } & \text { S } & \text { T } & \text { A } & R & G & G & \text { W } & \text { S } & \text { C } & \text { T } & \text { S } & \text { A } & G & G & \text { S } & \text { W } & \text { K } & \text { S } & \text { A } & \text { L } & \text { H } & \text { G } & \text { E } & \text { S } & \text { C } & \text { P } & \text { G } & \text { A } & R & \text { S } & \text { Y } & \text { L } & \text { P } & \text { S } & \text { L } & \text { E } & \text { L } & \text { T }\end{array}$ 961 TTTCATTTCCATGGGGACACTGTGGCAATGGTGATGCATCCAGCGTGTCCTTGTGACCAGCACACACCGATAGCTGCTGTATGCACCCAGGACGGGTACATGGACTTTGAAGTCCTTGCT

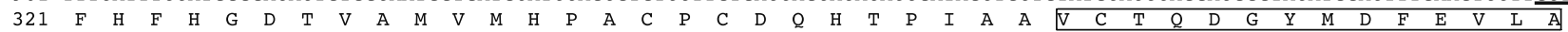
1081 GGCAGTACTACACCACCACTAGCCCTGGACACGCTCAGGCTCAGAGATCCCACATGCAAACCTGCCTCCAGGTCCCCTTCGAATGACAGGGCCTGGTTTCATGTCCCACTGAGCGGGTGT $\begin{array}{lllllllllllllllllllllllllllllllllllllllllllllll}361 & \text { G } & \text { S } & \text { T } & \text { T } & \text { P } & \text { P } & \text { L } & \text { A } & \text { L } & \text { D } & \text { T } & \text { L } & \text { R } & \text { L } & \text { R } & \text { D } & \text { P } & \text { T } & \text { C } & \text { K } & \text { P } & \text { A } & \text { S } & \text { R } & \text { S } & \text { P } & \text { S } & \text { N } & \text { D } & \text { R } & \text { A } & \text { W } & \text { F } & \text { H } & \text { V } & \text { P } & \text { L } & \text { S } & G & \text { C }\end{array}$ 1201 GGGACCAGGTACTGGCTGGAAGGAGAGAAGATCATGTATGAGAACGAGGTGAGGGCGCTGCAGTCTGACCGTGTGCTGCACAGGATCTCGAGGGACAGTGAGTTCAGGTTAACAGTGCTC

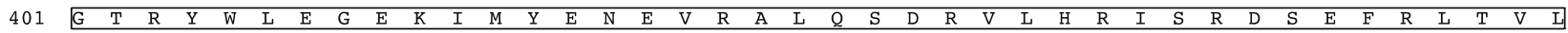
1321 TGCTCCTTCAGCAATGGCGATGCCTCTGTCTCTGTAAGGGTTGACAGCCCTCCCCCCCTGGCTGCTTCCATGAACCAAGGCCCCCTCTCTTTAATCCTTCTAAGCTACCCAGAGGACTCG

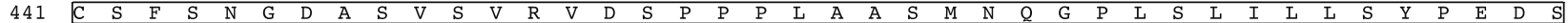

1441 TACAGGCAGCCGTACCGTGATGACCAGTACCCCATAGTGAGGTTCCTACAGCAGCCCATCTTCATGGAAGTGCAGGTCCTGAACCGCAATGACCCCAACCTCTACCTCCAACTGGACGAC

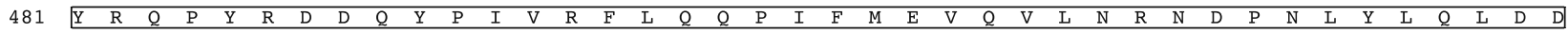
1561 TGCTGGGCAACTGCATCAGAAGATCCGAGCTCGCTTCCACAGTGGAATATTGTTGTTGATGGGTGTGAGTATGACCAGGACAGCCACAGGACCGTGTTCCATCCCATAGGCCATGGTGTC

521 C \begin{tabular}{llllllllllllllllllllllllllllllllllllllllll} 
& W & A & T & A & S & E & D & P & S & S & L & P & Q & W & N & I & V & V & D & G & C & E & Y & D & Q & D & S & H & R & T & V & F & H & P & I & $G$ & H & $G$ & V \\
\hline
\end{tabular} 1681 AGCTATCCCAACTACCGCCGGCGGCTGGAAGTGAAGGCTTTTGCTTTCATGTCTGGTGACAAGGCCCTCCCCAGCTTAGTGTATTTCCACTGCAGTGTCCTCATCTGCAACCGCTTCCAG \begin{tabular}{lllllllllllllllllllllllllllllllllllllllll}
561 & $\mathrm{~S}$ & Y & P & N & Y & R & R & R & L & E & V & K & A & F & A & F & M & S & G & D & K & A & L & P & S & L & V & Y & F & H & C & S & V & L & I & C & N & R & F & Q \\
\hline
\end{tabular} 1801 CCAGACTCCCCCCTGTGCACAGCGAGGTGCCCCAGGCTGCCTAGAAGCAAGAGAGGCAGTGGGATGCCGGGGGCCAGCTCTGTGGTGAGCCTGCAGGGTCCTGTGCTCCTGGTGCCCCAC

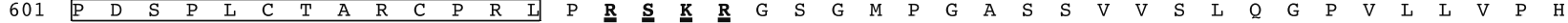
1921 GGATGGGCAGCAGCACAAGGGGATGTTCTGCTGAGCGAGGCTGCGTGGGCTGCAGTTACTGTGGCTGCTGTTGGTGCTCTCTCTCTGGTGACCGCAATGCTGCTATTTATGGCTCTTCTT 641 G 2041 AAATGCCTGAAGAGAAGAGCCCTGATGGTAAATGTGGTACATTAATATGTTTGTTAATGAACTTAATTAAAAATGTGGCTTTTCAGTTAAGAGATGTAAAAAAAAAAA

$\begin{array}{llllllllllllllllllllllll}681 & K & C & L & K & R & R & A & L & M & V & N & V & V & H & *\end{array}$

B Quail

Chicken

MR--LLLLLLVGFLLFLAPGASGQWDLSESTTCLQDRLELELPTELGNYTWHARAVDVSG

Quail

Chicken

EEMASCELTVDYEKLLLSALLVNCTSLEHGQHQLRLLLLLNGTAGEERNVTFSARCSAAR

Quail

Chicken

GDEI IAPVFVGATNCTKDSMAVTF PGPSLGNERPVQVAALPRTLVIDDGTRVHOLSPGEA

Quail

Chicken

SQHGYSFQADGHSLVLQAAFTATGVVSYQHNHKVLYTAAVKLTYGPPEHRLTMESRMLCA

Quail

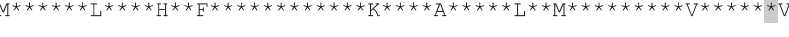

Chicken

$\underset{* * \star * *}{\text { PGPVLCNTTHMTVAVPAFPGTLVSVAVEDETIPMDRLQDNGITLSTARGGWSCTSAGGSW }}$

Quail

Chicken

KSALHGESCPGARSYLPSLELTFHFHGDTVAMVMHPACPCDQHTPIAAVCTQDGYMDFEV
$* * T^{*} * * * * *$ RVQ

Quail

Chicken

LAGSTTPPLALDTLRLRDPTCKPASRSPSNDRAWFHVPLSGCGTRYWLEGEKIMYENEVR

Quail

Chicken

ALQSDRVLRRISRDSEFRLTVLCSFSNGDASVSVRVDSPPPLAASMNQGPLSLILLSYPE

Quail

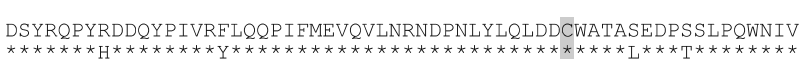

Chicken

VDGCEYDQDSHRTVFHPIGHGVSYPNYRRRLEVKAFAFMSGDKALPSLVYFHCSVLICNR

Quail

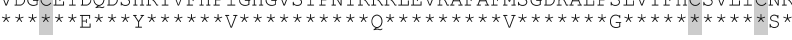

Quail

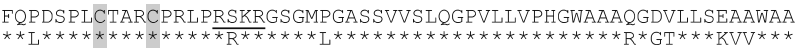

Quail

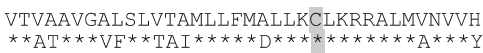

Figure 1 (A) Nucleotide and deduced amino acid sequences of quail ZP2 cDNA. The deduced amino acid is represented as a single-letter abbreviation shown below the nucleotide sequence (GenBank accession number: AB295393). The signal sequence (italic letters), the zona pellucida domain (ZP domain, white box), the consensus site for $\mathrm{N}$-glycosylation (bold letters), the consensus furin cleavage site (bold letters with underlining), a polyadenylation signal sequence (underlining), and the putative transmembrane domain (shaded box) are indicated. The asterisk indicates the termination codon. Primer positions used for amplifying the probe for RNase protection assay (hatched underlines) and the antigen production for anti-ZP2 antiserum (double underlines) and probe for in situ hybridization (bold underline) are shown. (B) Alignment of amino acid sequence of quail and chicken ZP2. Conserved residues are shown in asterisk and the consensus site for $\mathrm{N}$-glycosylation in bold letters; the consensus furin cleavage site is underlined. Conserved Cys residues are indicated with a shaded box. 


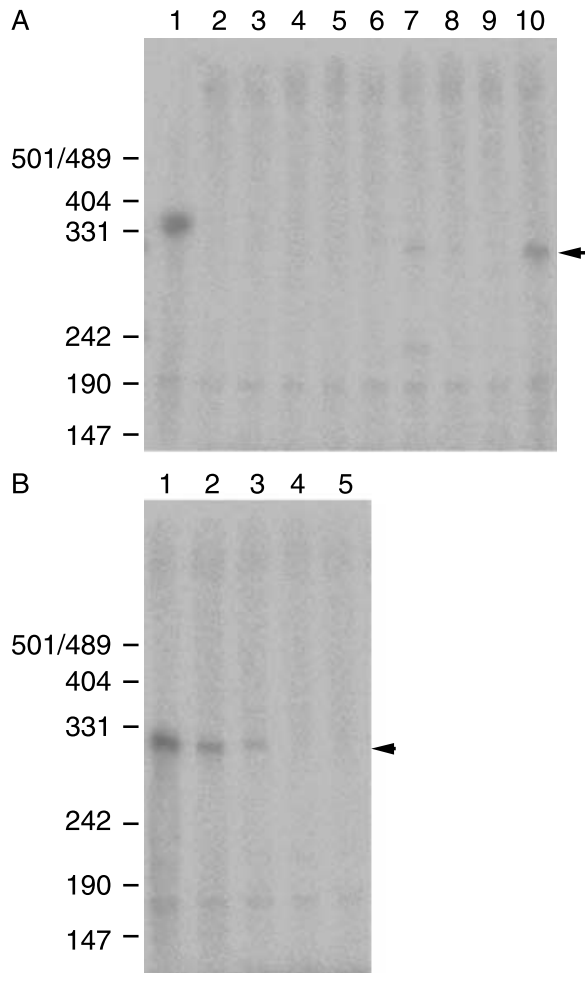

Figure 2 Tissue-specific expression of $Z P 2$ mRNA. (A) RNase protection assays were performed to detect the mRNA expression of the $Z P 2$ gene. We hybridized $15 \mu \mathrm{g}$ total RNA isolated from brain (lane 2), heart (lane 3), lung (lane 4), liver (lane 5), spleen (lane 6), kidney (lane 7), oviduct (lane 8), adrenal gland (lane 9), and SWF (lane 10) with riboprobes specific to $Z P 2$. As a reference, the antisense probe used in this experiment was run on the left lane (lane 1). Protected fragments were detected by autoradiography. The results shown are representative of repeated experiments. (B) Expression pattern of ZP2 mRNA during follicular development. The $15 \mu \mathrm{g}$ total RNA prepared from SWF (lane 1), large white follicles (lane 2), small yellow follicles (lane 3), the follicular wall of the second (lane 4), or the largest follicles (lane 5) were hybridized with riboprobes specific to ZP2. Representative autoradiograms of triplicate experiments are shown.

remove the unhybridized regions, which are derived from the pGEM-3Z vector during the synthesis of RNA probes. These results demonstrated that the expression of the $Z P 2$ gene is restricted to the ovary of the quail.

The temporal accumulation of the $Z P 2$ transcripts during follicular development was observed by an RNase protection assay. As shown in Fig. 2B, the band of the protected fragment in the SWF as well as large white follicles (LWF) was seen (lanes 1 and 2), whereas the intensity of the band dramatically decreased when the RNA derived from the small yellow follicles (SYF) was detected (lane 3). Because mature follicles like F1 and F2 are large, we could not isolate the RNA from the whole follicles; however, the protected fragment was not detected when the sample was prepared from the follicular wall of F2 (lane 4) as well as F1 (lane 5). These results are in accord with the in situ hybridization data (Fig. 3A), where the intense signal was detected in the SWF $(<1 \mathrm{~mm}$ in diameter). No detectable signals were seen in the case of the mature follicles including F1, F2, or F3. Again, no such intense signal was detected in any other specimens hybridized with the sense probe (Fig. 3B). These results clearly suggest that the expression of the ZP2 gene in the follicles is progressively decreased during follicular development and that the high expression is seen in the immature follicles, especially in SWF.

To further localize the expression of $Z P 2$ transcripts in the follicles, we observed the hybridized specimens under dark-field microscopy (Fig. 3C). As shown in the figure, the intense signals were observed in most of the oocyte of the SWF (asterisks in Fig. 3C), suggesting that the $Z P 2 \mathrm{mRNA}$ appears to be transcribed in the oocyte itself. The specimens that had been hybridized with the sense probe did not contain these radiolabeled signals (insert in Fig. 3C). These results suggest that the expression of the $Z P 2$ gene is restricted in the oocyte of the SWF and that the expression is decreased during follicular development.

\section{Presence of ZP2 protein in the oocytes}

To confirm the presence of the ZP2 protein in the oocytes, we produced an antiserum against bacterially expressed quail ZP2. As shown in the Fig. 4, the purified recombinant ZP2 showed a single band migrating $\sim 63 \mathrm{kDa}$ in molecular mass after the gels were stained with $\mathrm{CBB}$ (Fig. 4A, lane 2). We immunized this protein to a rabbit, and the antiserum against quail ZP2 was obtained. To visualize the ZP2 protein in the SWF extract, we performed western blot analysis. As shown in Fig. 4B, our anti-ZP2 antibody reacted well with the band with $80 \mathrm{kDa}$ in the SWF extract under nonreducing conditions (Fig. 4B, lane 1). No band was detected when the sample was reacted with preimmunoserum (Fig. 4B, lane 2), which suggests that our anti-ZP2 antibody is specific to $80 \mathrm{kDa} Z \mathrm{ZP} 2$ proteins. These results suggest that the immunoreactive materials that reacted with anti-ZP2 antibody exist in the SWF extract.

To investigate the localization of ZP2 protein in the follicles, we prepared paraffin sections of LWF and analyzed them by immunohistochemistry. As shown in Fig. $5 \mathrm{~A}$, the immunoreactive material recognized by anti-quail ZP2 antibody accumulated in the region beneath the apical surface of the granulosa cells, and was observed as a narrow line (arrow). Positive immunoreactions were also seen in the cytoplasm of the oocyte (arrowheads). The immunoreactive materials are not yolk-derived materials, because the yolk granules seen inside the oocyte were not stained with anti-quail ZP2 antibody. No positive immunostaining was seen when the sections were incubated with preimmunoserum (insert, Fig. 5). These results indicate that ZP2 protein is localized in the oocyte and that it could be selectively transported toward the surface of the cells. 

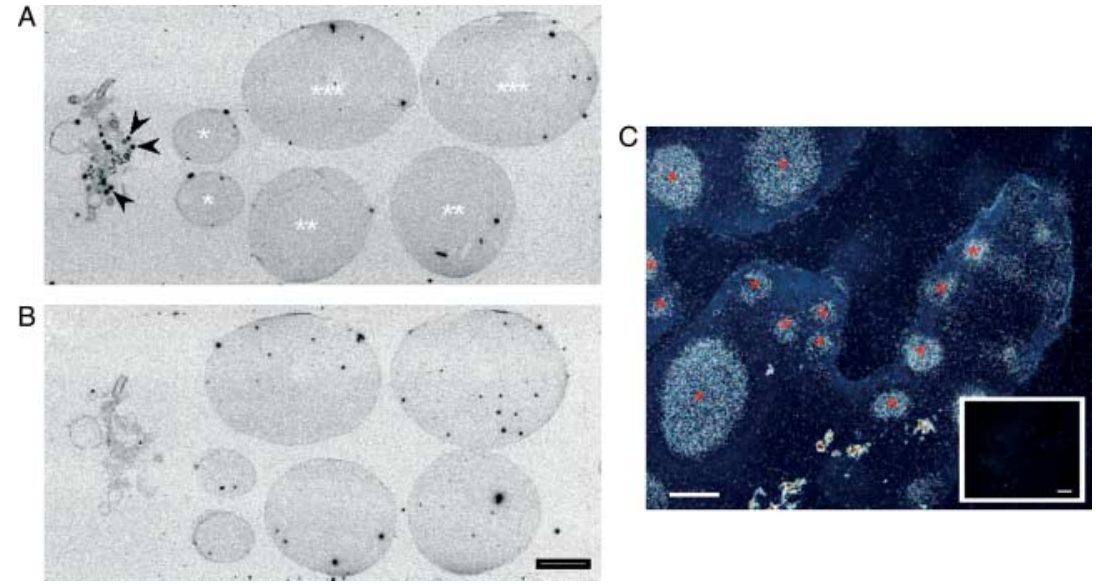

In order to further investigate the localization of ZP2 protein in the oocyte of the SWF, we performed ultrastructural observations on the SWF of quail ovary (Fig. 6). In accordance with the results of the immunohistochemistry, immunoelectron microscopy revealed the presence of immunoreactive ZP2 in the oocyte. In SWF of $1.3 \mathrm{~mm}$ in size, the gold particles are mainly localized in the region called 'zona radiata', which located just below the follicular granulosa cells (panel A, arrows). Although limited in number, the gold particles were found in the perivitelline space (PS) between the granulosa cells and oocyte (panel A). In addition, the particles were also observed in the cortical region of the cytoplasm in the oocyte (arrowheads). However, no such accumulations of the gold particles are seen in the granulosa cells. In the case of the SWF that were $0.7 \mathrm{~mm}$ in diameter, the border between the follicle cells and oocytes was obscure, but the immunogold particles appeared to be present dominantly in the oocyte (Fig. 6B). This statement is also supported by the quantitative analysis in that the number of the immunogold particles in the oocyte $\left(7.26 \pm 3.23 / \mu \mathrm{m}^{2}, n=10\right)$ is significantly greater than that in the granulosa cells $\left(4.37 \pm 1.13 / \mu \mathrm{m}^{2}, n=10 ; P<0.05\right)$. These results are consistent with the notion that the ZP2 proteins are mainly present in the oocyte but not in the granulosa cells of the quail ovary, and that the results obtained here are in accord with those from the light microscopy.

\section{Expression of recombinant ZP2 in the cultured Chinese hamster ovary-K1 cells}

Consistent with our previous report (Sasanami et al. 2006), quail ZP1 expressed in the cultured Chinese hamster ovary $(\mathrm{CHO})-\mathrm{K} 1$ cells was secreted from the cells during the culture, and the immunoreactive $97 \mathrm{kDa}$ band was seen in the conditioned medium of the transfected cells (Fig. 7 panel A, lane 3). Although the nature is unknown, we also detected the immunoreactive $45 \mathrm{kDa}$ band in addition to the $97 \mathrm{kDa} Z \mathrm{ZP} 1$ in the cell lysate (Fig. 7 panel A, lane 4). In contrast, in the ZP2 expression experiments, we found that the immunoreactive materials that migrated $\sim 80 \mathrm{kDa}$ and over 200 kDa in molecular mass were present in the cell

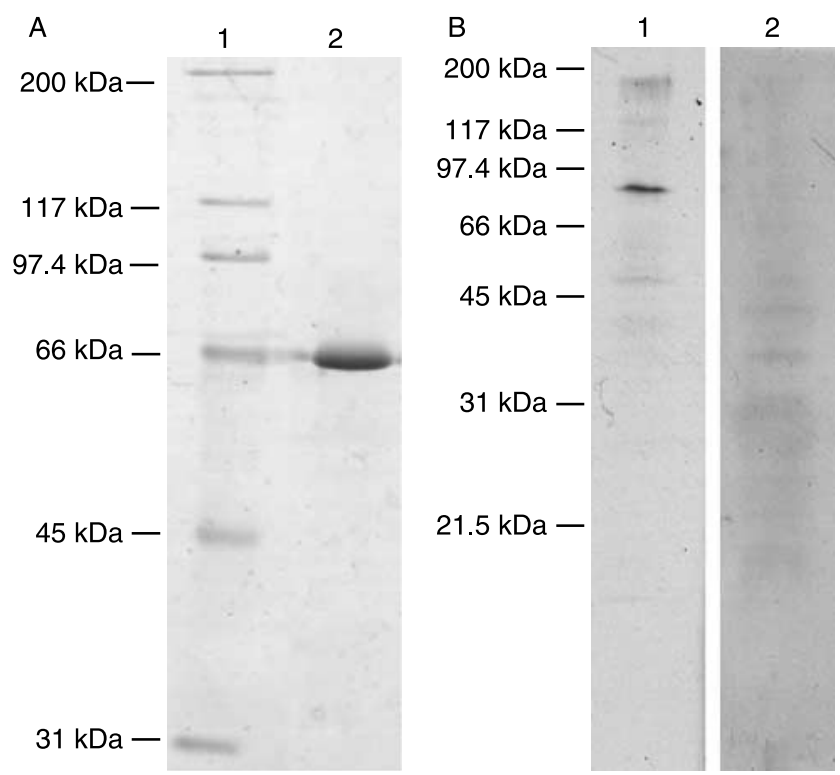

Figure 4 SDS-PAGE analysis of the purified recombinant ZP2 protein and western blot analysis of ZP2 protein in the extract of the SWF. (A) The purified recombinant ZP2 protein for immunization $(3 \mu \mathrm{g})$ was separated on SDS-PAGE under nonreducing conditions and stained with Coomassie brilliant blue R 250 (lane 2). A molecular weight marker was run in the next lane (lane 1). (B) The extracts prepared from the SWF (20 $\mu \mathrm{g} /$ lane) were separated on SDS-PAGE under nonreducing conditions, transblotted onto PVDF membrane, and detected with antiquail ZP2 antiserum (lane 1, 1:1000) or preimmunoserum (lane 2,

1:1000). The results representative of repeated experiments are shown. 


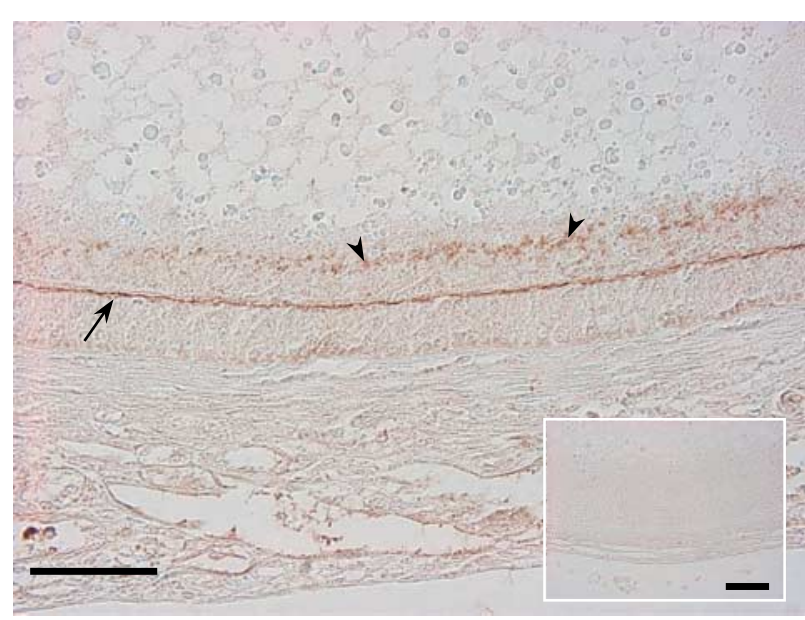

Figure 5 Immunohistochemical analysis of ZP2 in follicular wall. Sections of follicular wall obtained from LWF were processed for immunohistochemical observation using anti-quail ZP2 antiserum $(1: 250)$ or preimmunoserum (inset, 1:250). Arrow and arrowheads indicate the positive staining in the region beneath the apical surface of the granulosa cells and in the cytoplasm of the oocyte respectively. The results representative of repeated experiments are shown. Scale bar, $50 \mu \mathrm{m}$.

lysate (Fig. 7 panel B, lane 4), and no detectable band reacting with the anti-quail ZP2 antiserum was seen in the conditioned medium (Fig. 7 panel B, lane 3). These results indicate that the ZP2 that expressed in the cultured $\mathrm{CHO}-\mathrm{K} 1$ cells is not secreted from the cells during the culture.

We next investigated whether the recombinant ZP2 expressed in the cultured $\mathrm{CHO}-\mathrm{K} 1$ cells possessed the ability to interact with ZP3 protein. To achieve this goal, we prepared the conditioned medium of the granulosa layers which containing ZP3 protein. As shown in Fig. $8 \mathrm{~A}$, when the conditioned medium of the granulosa cells was detected with anti-ZP3 antiserum, the $35 \mathrm{kDa}$
ZP3 band was detected (lane 1). On the other hand, our anti-ZP2 antiserum (lane 2) as well as normal rabbit serum (lane 3 ) did not cross-react with ZP3 protein. To test the possible interaction of the cellular ZP2 and the ZP3, we cultured the ZP2-expressed cells or the mocktransfected cells in the presence or absence of the conditioned medium of the granulosa cells. The cell lysates after the culture were detected with western blot analysis using anti-ZP3 antiserum (Fig. 8B). As shown in the figure, when the $\mathrm{CHO}-\mathrm{K} 1$ cells that had been transfected with the $Z P 2$ gene were cultured in the presence of the conditioned medium, the immunoreactive ZP3 band was detected (lane 4). However, we did not detect the $35 \mathrm{kDa}$ band when the same cells were cultured in the absence of the conditioned medium (lane 3). In addition to the ZP3 band, the sample prepared from ZP2-transfected cells contained additional band migrating around $31 \mathrm{kDa}$ (lanes 3 and 4); however, it appeared to be a nonspecific protein because it was also detected in the mock-transfected cells cultured in the presence or absence of the conditioned medium (lanes 1 and 2). To further localize the ZP3 protein in the cells, we observed these cells by means of immunofluorescence microscopy. As shown in the Fig. 9, when the ZP2 transfected cells cultured with the conditioned medium were detected, the immunoreactive materials with antiZP3 antiserum were seen as agglomerate on the surface of the cells. In the case of the cells that were cultured without the conditioned medium of the granulosa cells, we failed to detect such structure that reacted with antiZP3 antiserum (inset). Taken collectively with the data in Fig. 8, these results are consistent with the notion that the ZP3 protein in the conditioned medium of the granulosa cells could interact with cellular ZP2 that expressed in the $\mathrm{CHO}-\mathrm{K} 1$ cells, and that these complex might lead to the formation of an amorphous structure on the cells.
A

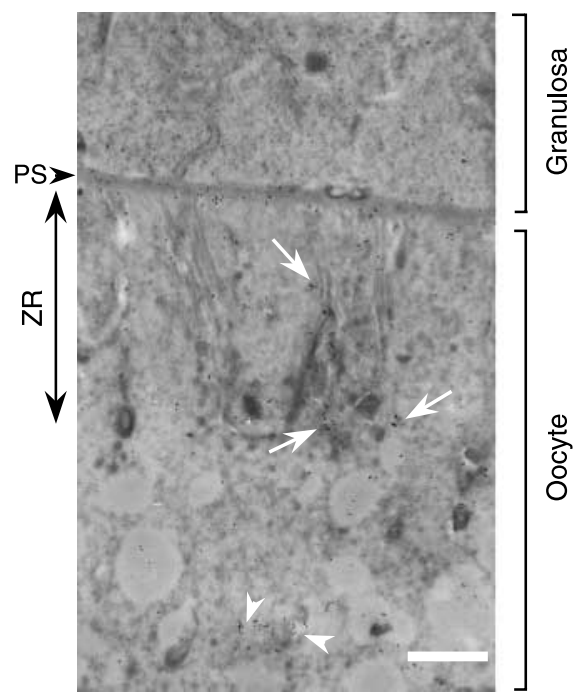

B

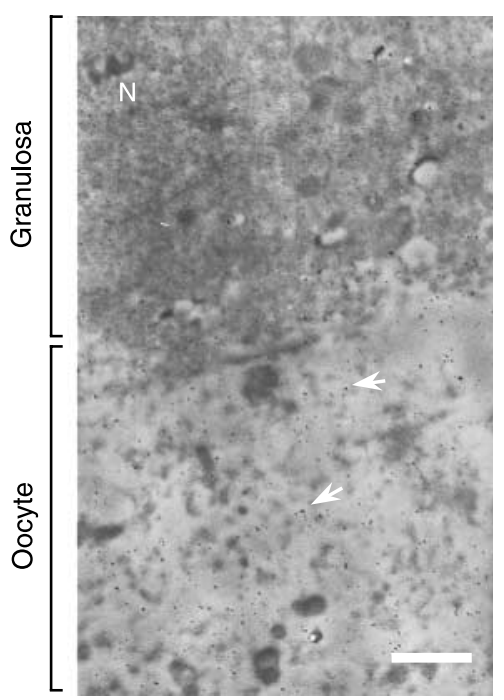

Figure 6 Immunoelectron micrographs of SWF. Ultra thin sections of follicular wall of $1.3 \mathrm{~mm}$ (A) or $0.7 \mathrm{~mm}$ (B) follicles were stained with anti-quail ZP2 antiserum. (A) Accumulations of the gold particles are frequently found in zona radiata (arrows), perivitelline space, as well as cortical region of the oocyte below the zona radiata (arrowheads). In contrast, no such accumulation is not seen in the granulosa cells (B) In $0.7 \mathrm{~mm}$ follicles, immunogold particles are evenly localized in the cytoplasm of the oocyte (arrows). The results representative of repeated experiments are shown. Scale bar, $1 \mu \mathrm{m}$. PS, perivitelline space; ZR, zona radiata; $\mathrm{N}$, nucleus. 


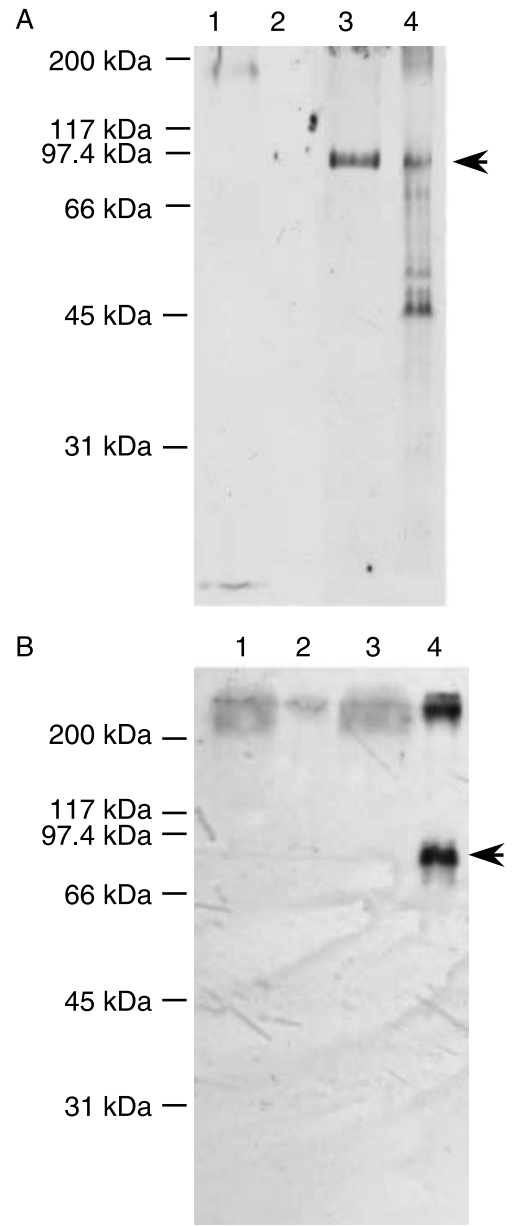

Figure 7 Western blot analysis of recombinant ZP1 and ZP2 expressed in the cultured $\mathrm{CHO}-\mathrm{K} 1$ cells. (A) $\mathrm{CHO}-\mathrm{K} 1$ cells transfected with vector alone (lanes 1 and 2) or quail ZP1 expression construct (lanes 3 and 4) were cultured for $48 \mathrm{~h}$, and the medium and cell lysates were recovered. They were then concentrated, and the medium (lanes 1 and 3; $16 \mu \mathrm{l}$ per lane) and cell lysates (lanes 2 and 4; $10 \mu \mathrm{g}$ protein per lane) were probed with anti-quail ZP1 antiserum (1:1000 dilution). (B) Quail ZP2 expression construct (lanes 3 and 4) or vector alone (lanes 1 and 2) was introduced into CHO-K1 cells, and the medium (lanes 1 and 3; $16 \mu \mathrm{l}$ per lane) and the cell lysates (lanes 2 and 4; $10 \mu \mathrm{g}$ protein per lane) after $48 \mathrm{~h}$ of culture were detected with anti-quail ZP2 antiserum as described above. The immunoblots shown are representative of three experiments.

\section{Discussion}

In a previous study, we found that quail granulosa cells produce ZP3, which is one of the major components of the PL (Pan et al. 2001), whereas another constituent, ZP1, is synthesized in the liver (Sasanami et al. 2003b). $A$ recent study has revealed that another minor constituent, ZPD, was produced and secreted from the granulosa cells in Japanese quail (Sato et al. 2009). In the present study, we clearly demonstrated that both the mRNA for ZP2 and the ZP2 protein are present in the oocytes of immature follicles in the quail ovary. To our knowledge, this is the first demonstration that avian ZP glycoprotein is expressed in the oocyte itself. The sources of ZP glycoproteins are different in different species (Menkhorst \& Selwood 2008). In most mammalian species including mice, there is clear evidence showing that ZP glycoproteins are synthesized by the growing oocytes (Bleil \& Wassarman 1980). In X. laevis, they are also expressed in the oocytes (Yamaguchi et al. 1989). In addition to the oocytes-restricted expression, the follicular granulosa cells also contribute to the synthesis of ZP3 in rabbits (Lee \& Dunbar 1993) and in cynomolgus monkeys (Martinez et al. 1996). On the other hand, glycoproteins homologous to ZP glycoproteins in chorion, the fish egg envelope, are produced in the liver and transported to the ovary by the blood circulation, like vitellogenin (Hamazaki et al. 1985, 1989), whereas the egg envelope glycoproteins of carp (Cyprinus carpio), goldfish (Carassius auratus), and zebrafish (Danio rerio) appear to be derived from an ovarian source (Conner \& Hughes 2003). Our experimental evidence strongly suggests that female germ cells (i.e., the oocyte) also participate in producing the $Z P$ glycoprotein in addition to the ovarian granulosa cells (ZP3 and ZPD) and the liver (ZP1) in avian species. This is a unique case in which three types of cells (hepatocytes, ovarian granulosa cells, and oocytes) participate in the production of ZP glycoproteins in vertebrate animals (Menkhorst \& Selwood 2008). It might be due to the size of the avian oocytes that are far larger than those of fish, amphibian, and mammalian species, and that the glycoproteins synthesized and secreted from oocyte and granulosa cells are insufficient to cover the surface area of the big oocytes in birds. We suppose that an active organ in protein synthesis, such as liver, should participate in the synthesis of the ZP glycoproteins in avian species.

The immunological studies with anti-quail ZP2 antiserum showed that immunoreactive material accumulates in the zona radiata located between the granulosa cells and oocyte (Fig. 6), and that the apparent molecular mass is $\sim 80 \mathrm{kDa}$ (Fig. 4B). The immunoreactive materials are also present in the cortical region of the cytoplasm of the oocyte (Figs 5 and 6), supporting our statement that the ZP2 proteins are produced by the oocyte. It is interesting to note that the ZP2 expressed in the cultured $\mathrm{CHO}-\mathrm{K} 1$ cells is not secreted, but instead remains in the cell lysate (Fig. 7), and that this phenomenon could be related to the localization of the ZP2 protein in zona radiata, which is constructed from the microvilli of oocyte and the surrounding follicle cells (Ito et al. 2003). We think, therefore, that after translation, the ZP2 proteins are selectively transported toward the apical surface of the oocyte, which are apposed to the PS where the fibers of the PL start to accumulate when the follicles begin to grow (Ito et al. 2003).

In the present study, we found that the transcripts of ZP2 protein in the follicles decreased during follicular 

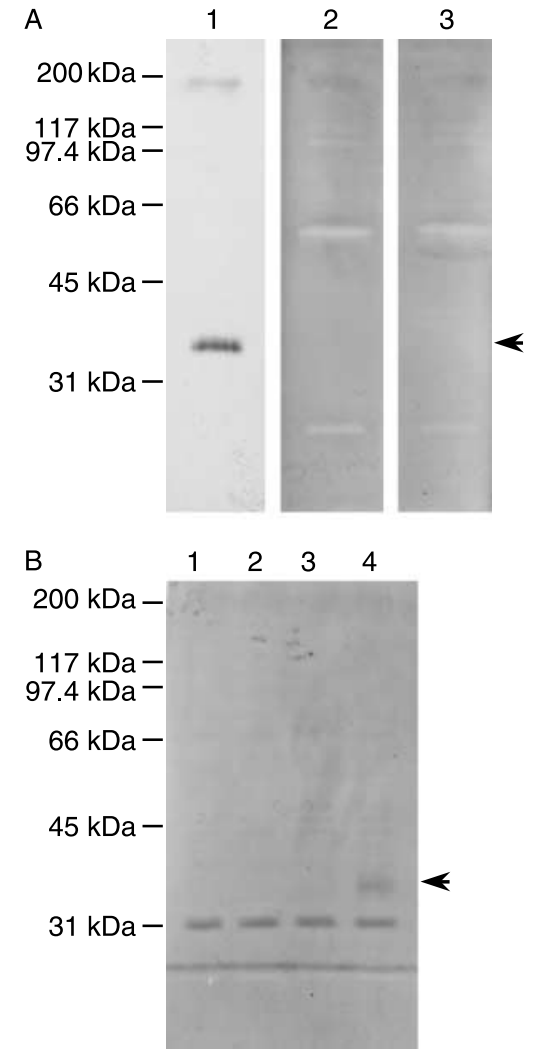

Figure 8 Western blot analysis of ZP3 protein interaction with recombinant ZP2. (A) Granulosa layers were cultured for $8 \mathrm{~h}$, and the ZP3 protein in the medium ( $14.4 \mu \mathrm{l}$ of the culture medium per lane) was detected by using anti-quail ZP3 antiserum (lane 1, 1:10 000), antiquail ZP2 antiserum (lane 2, 1:500), or normal rabbit serum (lane 3, 1:500). Immunoblots shown are representative of at least three experiments. (B) CHO-K1 cells transfected with vector alone (lanes 1 and 2) or quail ZP2 expression construct (lanes 3 and 4) were cultured for $48 \mathrm{~h}$ in the presence (lanes 2 and 4 ) or absence (lanes 1 and 3 ) of the conditioned medium of the granulosa cells, and the cell lysates were recovered. They were then detected with western blotting as described in Materials and Methods ( $10 \mu \mathrm{g}$ protein per lane). The representative results of three experiments are shown.

development, and the mRNA for $Z P 2$ was not detected at the latter stages of folliculogenesis (Fig. 2B). This pattern is very different from that for the other ZP glycoproteins in quail, in that immunoreactive ZP3 appears as early as in the PL obtained from the SYF, and the ZP1 and ZPD accumulate thereafter (Pan et al. 2001, Sasanami et al. 2004, Sato et al. 2009). In mice, Epifano et al. (1995) investigated the accumulation of ZP1, ZP2, and ZP3 transcripts in oocyte lysates during oogenesis using an RNase protection assay. They showed that the transcript of ZP2 was detected as early as in the lysates of the resting oocyte at the prophase stage, whereas the accumulation of the ZP1 and ZP3 transcripts became detectable after the oocytes began to grow. Although the origins of the ZP glycoproteins are different from each other, the expression of quail ZP glycoproteins is also likely regulated in a coordinate manner, as in the case of the mouse ZP glycoproteins.

In the mouse ZP, ZP2 and ZP3 are present in roughly equimolar amounts and polymerise to form a long chain of heterodimer (Wassarman \& Litscher 2008), whereas ZP2 protein in the PL of the largest follicles in quail ovary was at an undetectable level (data not shown). As was mentioned earlier, the PL in quail as well as in chicken is constructed mainly by ZP1 and ZP3, and these components specifically bind to form the PL fiber (Ohtsuki et al. 2004, Sasanami et al. 2006, Okumura et al. 2007a, 2007 b, Kinoshita et al. 2008). In fact, in vitro incubation of ZP1 with ZP3 spontaneously produced fibrous aggregates, which were visible under optical microscopy (Okumura et al. 2007b). In addition, Okumura et al. (2007a) reported that the ZP1 and ZP3 were observed to colocalize on the surface of ZP3-expressing transfectants cultured in the presence of the hen serum, and they suggested that ZP1 transported via blood circulation into the ovary encounters and associates with ZP3 secreted from granulosa cells, resulting in the formation of heterocomplexes around the oocyte. In our previous study, however, when the ZP3 expression construct had been introduced into the CHO-K1 cells, we observed that most of the ZP3 were secreted away into the medium, and the immunoreactive substances were not localized on the cell surface (Sasanami et al. 2003a, 2003c). In the present study, we observed a detectable interaction of ZP2 and ZP3 by means of western blot analysis (Fig. 8) and immunofluorescence microscopy (Fig. 9). Although the direct evidence is not available, based on the fact that we could observe the interaction of ZP2 and ZP3, we propose that

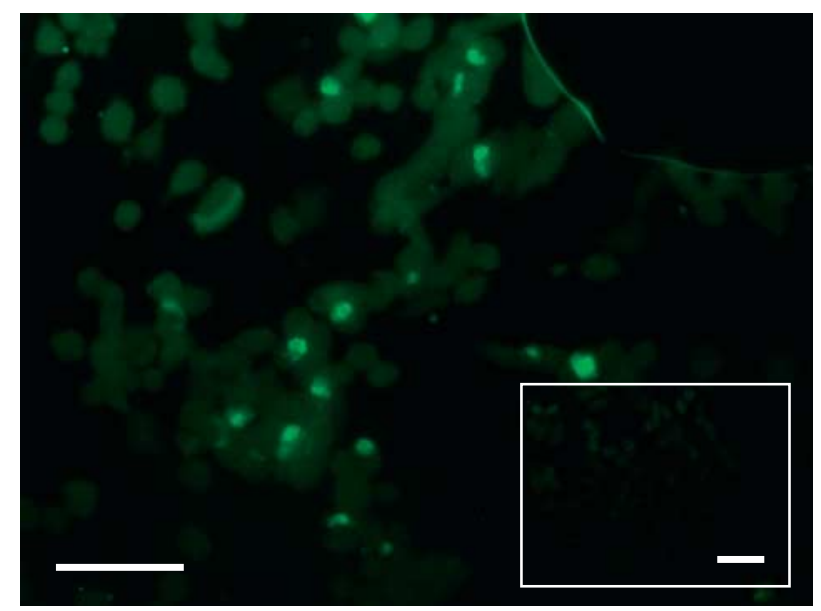

Figure 9 Immunocytochemical localization of ZP3 protein incorporated into the CHO-K1 cells. The CHO-K1 cells transfected with ZP2 expression construct were cultured for $48 \mathrm{~h}$ in the presence or absence (insets) of the conditioned medium of the granulosa cells, and the cells were stained with anti-quail ZP3 antiserum by means of immunofluorescence microscopy as described in Materials and Methods. The representative results of three experiments are shown. Scale bar, $50 \mu \mathrm{m}$. 
the ZP2 protein localized on the surface of the oocyte might be a target molecule for ZP3 binding, and that this interaction might in fact trigger the ZP glycoprotein accumulation (e.g. ZP3 and ZP1 heterocomplex formation) for the construction of the PL in the follicles. This hypothesis is also supported by the observation of the coordinate expression patterns of ZP glycoproteins described in the present study (ZP2) and our previous studies (ZP1, ZP3, and ZPD). From this view, we believe that the interaction of ZP1 and ZP3 might be important for the formation of the $\mathrm{PL}$ in the latter stage of the follicular development, especially in the yolk-filled yellow follicles, and that our present finding consistent with the interaction of ZP2 and ZP3 might shed new light on the mechanisms of the initiation step for the PL formation in the immature follicles of the quail ovary. Further studies are needed to uncover the mechanism of the formation of PL fibers during follicular maturation.

\section{Materials and Methods}

\section{Animals and tissue preparation}

Female Japanese quail, Coturnix japonica, 15-30 weeks of age (Tokai-Yuki, Toyohashi, Japan), were maintained individually under a photoperiod of $14 \mathrm{~h}$ light:10 $\mathrm{h}$ darkness (with the light on at 0500) and were provided with water and a commercial diet (Tokai-Hokuriku Nosan, Chita, Japan) ad libitum. The animals were decapitated, and the preovulatory follicles were dissected and placed in physiological saline. The follicular walls were peeled off the large yolk-filled follicles by fine forceps, and the adhering yolk materials were washed away by a gentle stream of water from a Pasteur pipette. All experimental procedures for the use and the care of animals in the present study were approved by the Animal Care Committee of Shizuoka University (approval number, 20-11).

\section{cDNA cloning of quail ZP2}

Total RNA was extracted from the SWF $(\sim 1 \mathrm{~mm}$ in diameter) with a commercial kit, RNAiso (Takara Biomedicals, Otsu, Japan), according to the manufacturer's instructions. Messenger RNA was isolated using an oligotex-dT30 mRNA purification kit (Takara Biomedicals), according to the manufacturer's instructions, and was reverse transcribed using a SuperScript II First-Strand Synthesis System for RT-PCR kit with oligo (dT) primer (Invitrogen). PCR was performed using degenerate primers (sense primer, 5'-GGMATVYDYSYKYRGTGGAT-3'; antisense primer, 5'-GTCCWRDTYRTAYKCACASCCATC-3') designed from the alignment of available sequences of chicken (GenBank accession number: AB197938), mouse (GenBank accession number: M34148), rat (GenBank accession number: AB000929), human (GenBank accession number: BC096305), dog (GenBank accession number: U05779), cat (GenBank accession number: U05776), and cow ZP2 (GenBank accession number: AB042653). PCR was performed in a $50 \mu \mathrm{l}$ volume with PCR buffer, $5 \mathrm{mmol} / \mathrm{ml} \mathrm{MgCl}_{2}, 0.4 \mathrm{mmol} / \mathrm{ml}$ dNTP, and 2.5 U Taq DNA polymerase (Takara EX Taq, Takara
Biomedicals). Following the addition of cDNA as the template, the reaction mixtures were incubated at $94{ }^{\circ} \mathrm{C}$ for $1 \mathrm{~min}$ and amplified for 30 cycles. Each cycle consisted of $30 \mathrm{~s}$ denaturation at $94{ }^{\circ} \mathrm{C}, 30 \mathrm{~s}$ annealing at $65.3{ }^{\circ} \mathrm{C}$, and $1.5 \mathrm{~min}$ elongation at $72{ }^{\circ} \mathrm{C}$. The amplicon was separated on $1.0 \%(\mathrm{w} / \mathrm{v})$ agarose gel electrophoresis, and a band of the expected size was eluted from the gel with a Rapid gel extraction system (Marligen Bioscience, ljamsville, MD, USA) according to the manufacturer's instructions. Purified DNA was subcloned into pT7 Blue T-Vector (Novagen, Madison, WI, USA) and sequenced by dye terminator chemistry on an Applied Biosystem Model 310 sequencer by the dideoxy-mediated chain termination method (Sanger et al. 1977). Based on the sequence information of the presumptive ZP2 cDNA ampliCon, $3^{\prime}$-RACE was performed using the $3^{\prime}$-RACE System for RACE (Invitrogen). A gene-specific primer (5'-GCTTTCATGTCTGGTGACAAGG-3') in combination with adaptor primers was used for 3'-RACE. For 5'-RACE, cDNA was synthesized with a gene-specific primer (5'-AACAAAGACAGGAGCGATGATTT-3'), and a RACE reaction was performed using the 5'-RACE System for RACE, Version 2.0 (Invitrogen). The genespecific primer in combination with adaptor primers used was 5'-CCGTGCTCCAGGCTGGTGCAGTT-3'. This amplicon was re-amplified with the nested gene-specific primer (5'-AGAGATCCCATTGCCCTGAGGCAG- $3^{\prime}$ ) in combination with adaptor primers. RACE amplicons were subcloned and sequenced as described above.

\section{Sequence computations}

Homology search by the position-specific iterated, basic local alignment search tool (PSI-BLAST) method (Altschul et al. 1997) and alignment of multiple protein sequences by the CLUSTAL W method (Thompson et al. 1994) were performed using the DNA Data Bank of Japan (http://www.ddbj.nig.ac.jp). The signal peptide and its putative cleavage site were predicted according to Nielsen et al. (1997) using SignalP v2 (http://www. cbs.dtu.dk/services/SignalP/).

\section{RNase protection assay}

Total RNA was extracted from brain, heart, lung, liver, spleen, kidney, oviduct, adrenal gland, and SWF of laying female birds as described above.

PCR-amplified fragments derived from quail ZP2 CDNA (350 nt; 148-494 of GenBank accession number AB295393) were subcloned into a pGEM-3Z vector (Promega Corporation). After linearization with the appropriate restriction enzymes, radioactive antisense or sense riboprobes were synthesized using Riboprobe in vitro Transcription System (Promega Corporation) and $\left[\alpha_{-}^{32} \mathrm{P}\right]$ CTP (NEN Life Science Products, Boston, MA, USA). The RNA probes were hybridized with total RNA overnight and digested with RNase A and T1 (Tanaka et al. 1999). The protected RNAs were separated on $6 \%(\mathrm{w} / \mathrm{v})$ polyacrylamide/urea gels. The radioactive bands on the dried gels were detected with autoradiography with the aid of an intensifying screen (Kodak). 


\section{In situ hybridization}

The birds were decapitated, the follicles were immediately removed, and frozen sections were prepared. In situ hybridization was carried out as described previously (Yoshimura et al. 2000). The antisense 45 mer oligonucleotide probe (nucleotides 1078-1122 of GenBank accession number AB295393) was labeled with $\left[{ }^{33}\right.$ P] dATP (NEN Life Science Products) using terminal deoxyribonucleotidyl transferase (Gibco). The sense probe was also labeled as described above. Hybridization was carried out overnight at $42{ }^{\circ} \mathrm{C}$. Washing was performed at room temperature for $30 \mathrm{~min}$ and at $55^{\circ} \mathrm{C}$ for $40 \mathrm{~min}$ twice. After washing, slides were exposed to Biomax MR film (Kodak) for 2 weeks. After the exposure, the slides were coated with Kodak NTB-2 emulsion (Kodak), and exposed for 7 days at $4{ }^{\circ} \mathrm{C}$ in a dark box. After exposure, the slides were developed in Kodak Dektol and mounted in glycerol. The specimens were examined under a dark-field microscopy with an $\times 40$ objective (Nikon, Tokyo, Japan).

\section{Production of antiserum against quail ZP2}

Rabbit polyclonal anti-quail ZP2 antibody was raised against bacterially expressed His tag fused with partial ZP2 protein (from Thr $^{134}$ to $\mathrm{Leu}^{236}$ ). Quail ZP2 cDNA was amplified by PCR (cycling conditions: $94^{\circ} \mathrm{C}$ for $1 \mathrm{~min}, 61^{\circ} \mathrm{C}$ for $1 \mathrm{~min}$, and $72{ }^{\circ} \mathrm{C}$ for $1 \mathrm{~min}$ for 30 cycles) in order to introduce Xhol and EcoRI sites upstream of the $\mathrm{Thr}^{134}$ and downstream of the Leu ${ }^{236}$ respectively. The sense and antisense primers used were 5'-AAAACTCGAGACAAAGGATTCCATGGCAGTT- ${ }^{\prime}$ ' and 5'-CGGAATTCAAGCATTCTTGACTCCATGGT-3' respectively. The PCR product containing the partial quail ZP2 CDNA was digested with Xhol and EcoRl, and ligated into pCold TF DNA vector (Takara Biomedicals) treated with the same restriction enzymes. The resulting construct was transformed into competent Escherichia coli, strain BL21 (Takara Biomedicals), and an ampicillin-resistant clone was selected after the nucleotide sequence analysis was performed. Recombinant quail ZP2 was expressed as the $63 \mathrm{kDa}$ fusion protein $(11 \mathrm{kDa}$ of the partial ZP2 protein with $52 \mathrm{kDa}$ of the trigger factor plus the His tags) in the presence of $1 \mathrm{mmol} / \mathrm{ml}$ isopropyl- $\beta$ thiogalactopyranoside at $15^{\circ} \mathrm{C}$ for $24 \mathrm{~h}$, and the protein was purified from the cell lysate using nickel resin (Novagen) according to the manufacturer's instructions. The purity of the recombinant ZP2 was verified by separating the protein by SDS-PAGE followed by CBB staining.

A single female New Zealand White rabbit (SLC, Hamamatsu, Japan) was immunized with the recombinant quail ZP2 (300 $\mu$ g protein) as described previously (Kuroki \& Mori 1995).

\section{Gel electrophoresis and western blot analysis}

The SWF was homogenized in SDS-Tris (1\% (w/v) SDS buffered at $\mathrm{pH} 6.8$ with $70 \mathrm{mmol} / \mathrm{ml}$ Tris- $\mathrm{HCl}$ ), and the proteins were extracted with vigorous shaking overnight at $4{ }^{\circ} \mathrm{C}$. Insoluble materials were removed by centrifugation at $14500 \mathrm{~g}$ for
15 min, and clear supernatants served as SWF extracts. The protein concentration in each sample was determined using a BCA Protein Assay kit (Pierce, Rockford, IL, USA).

SDS-PAGE under nonreducing conditions was carried out as described previously (Laemmli 1970), using 10 and 5\% (w/v) polyacrylamide for resolving and stacking gels respectively. For western blotting, proteins separated on SDS-PAGE were transferred to a PVDF membrane (Immobilon-P, Millipore, Bedford, MA, USA; Matsudaira 1987). The membrane reacted with anti-quail ZP2 antiserum (1:1000) was visualized by means of a chemiluminescent technique (Amersham Pharmacia Biotech) using HRP-conjugated anti-rabbit IgG (Cappel, Durham, NC, USA) as a secondary antibody.

\section{Culture of granulosa cells}

The granulosa layers isolated from the largest follicles were placed into a six-well culture plate (Falcon Plastics, Los Angels, CA, USA) filled with $3 \mathrm{ml} \mathrm{Ham}$ 's F-12 (Dainippon Seiyaku, Osaka, Japan) supplemented with $10 \%(\mathrm{v} / \mathrm{v}) \mathrm{FCS}$, penicillin (100 units/ml), and streptomycin $(100 \mu \mathrm{g} / \mathrm{ml})$ at $39{ }^{\circ} \mathrm{C}$, and were incubated for $8 \mathrm{~h}$ in a humidified atmosphere with $5 \%$ $\mathrm{CO}_{2}$. After the incubation, the conditioned medium was collected and centrifuged at $10000 \mathrm{~g}$ for $10 \mathrm{~min}$ to remove cellular debris. The conditioned medium was analyzed with western blot analysis using anti-quail ZP2 antiserum (1:500), anti-quail ZP3 antiserum (Kuroki \& Mori 1995; 1: 10 000), or normal rabbit serum (1:500) antiserum (Ohtsuki et al. 2004) as described above.

\section{Expression of ZP2 in a mammalian cell line}

Quail ZP2 cDNA was amplified by PCR (the cycling conditions: $94{ }^{\circ} \mathrm{C}$ for $30 \mathrm{~s}, 51.3{ }^{\circ} \mathrm{C}$ for $30 \mathrm{~s}$, and $72{ }^{\circ} \mathrm{C}$ for $2 \mathrm{~min}$ for 35 cycles) to introduce HindIII and Xbal sites upstream of the initiator methionine and downstream of the chain termination codons respectively. The sense and antisense primers used were $5^{\prime}$-AAAAAAGCTTGCAGCTCTGGCACTTTGAGGA-3' and 5'-GCTCTAGATTAATGTACCACATTTACC - $3^{\prime}$ respectively. The PCR product containing the full-length quail ZP2 cDNA was digested with HindIII and Xbal, and ligated into the mammalian expression plasmid vector pcDNA3.1(+) (Invitrogen) treated with the same restriction enzymes. The resulting quail ZP2 expression construct was transformed into competent E. coli, strain DH5 (Takara, Osaka, Japan). The sequence of the constructs was verified with DNA sequence analysis.

CHO-K1 cells generously provided by Dr Kazuhiko Imakawa (Department of Animal Breeding, University of Tokyo, Tokyo, Japan) were cultured in Ham's F-12 (Dainippon Seiyaku) supplemented with $10 \%$ FCS, penicillin (100 units/ml), and streptomycin $(100 \mu \mathrm{g} / \mathrm{ml})$ at $37^{\circ} \mathrm{C}$ in a humidified atmosphere with $5 \% \mathrm{CO}_{2}$. Before transfection, cells were plated into a six-well culture plate (Falcon Plastics) and cultured for $48 \mathrm{~h}$ until they had grown to $\sim 75 \%$ confluency. DNA $(2.5 \mu \mathrm{g})$ was introduced into the $\mathrm{CHO}-\mathrm{K} 1$ cells using Lipofectamine Plus Reagent (Gibco BRL) as suggested by the manufacturer, and the cells were cultured in fresh medium ( $3 \mathrm{ml} /$ well) for an additional $48 \mathrm{~h}$ to express recombinant ZP2. 
After the culture, the conditioned medium was collected and centrifuged at $10000 \mathrm{~g}$ for $10 \mathrm{~min}$ to remove cellular debris. The cells were washed twice with PBS $(\mathrm{pH} 7.4)$, scraped from the plates into SDS-Tris $(500 \mu \mathrm{l} /$ well), and dissolved by vigorous shaking. After centrifugation at $10000 \mathrm{~g}$ for $10 \mathrm{~min}$, clear supernatants were stored as total cell lysates. The protein concentration was determined as described above.

A quail ZP1 expression construct was generated and expressed in $\mathrm{CHO}-\mathrm{K} 1$ cells as described previously (Sasanami et al. 2006).

The cell lysates from ZP2-transfected cells and the conditioned medium derived from ZP1-expressing cells were concentrated to $\sim 1 / 10$ volume by using Amicon Ultra-4 centrifugal filter device (molecular mass cut off: $10 \mathrm{kDa}$, Millipore), and then analyzed with western blot analysis using anti-quail ZP2 antiserum (1:500) or anti-quail ZP1 antiserum (1:500) as described above.

\section{Analysis of the interaction of ZP2 and ZP3}

CHO-K1 cells transfected with vector alone or ZP2 expression construct were cultured for $48 \mathrm{~h}$ on $0.1 \%$ gelatin-coated coverslips in the conditioned medium of the granulosa cells $\left(3 \mathrm{ml} /\right.$ well) at $37^{\circ} \mathrm{C}$ in a humidified atmosphere with $5 \% \mathrm{CO}_{2}$. After the culture, the cells were fixed in $3.7 \%(\mathrm{v} / \mathrm{v})$ formaldehyde in PBS at room temperature for $30 \mathrm{~min}$, and were then permeabilized in cold acetone $\left(-20^{\circ} \mathrm{C}\right)$ for $5 \mathrm{~min}$. After being washed with PBS, the cells were incubated with PBS containing $3 \%(\mathrm{w} / \mathrm{v})$ gelatin for $1 \mathrm{~h}$, and were then incubated with anti-quail ZP2 antiserum (1:50) or anti-quail ZP3 antiserum (1:100) for $2 \mathrm{~h}$ at $4{ }^{\circ} \mathrm{C}$. After several washings with PBS, the specimens were reacted with FITC-conjugated goat anti-rabbit IgG (1:50, Cappel) for $1 \mathrm{~h}$ at $4{ }^{\circ} \mathrm{C}$. After several washings with PBS, the samples were embedded in glycerol, and were examined under a fluorescent microscopy (BX 50, Olympus Optics, Tokyo, Japan).

For the western blot analysis, the cells after the culture were washed twice with PBS, scraped from the plates into SDS-Tris $(500 \mu \mathrm{l} /$ well), and dissolved by vigorous shaking. After centrifugation at $10000 \mathrm{~g}$ for $10 \mathrm{~min}$, clear supernatants were detected using anti-quail ZP2 antiserum or anti-quail ZP3 antiserum as described above. The protein concentration was determined as described above.

\section{Immunohistochemical observation}

For localization of ZP2 in the follicle, the preovulatory follicles were dissected, fixed in Bouin's fixative, and embedded in Paraplast (Oxford Labware, St Louis, MO, USA). Immunohistochemical techniques using anti-quail ZP2 antiserum (1:300) or preimmunoserum (1:300) were described previously (Sasanami et al. 2002). The immunolabeled sections were examined under an interference contrast photomicroscope (BX 50, Olympus Optics).

\section{Immunoelectron microscopy}

For immunoelectron microscopy, relatively small and large SWF ( $\sim 0.7$ and $1.3 \mathrm{~mm}$ in diameter respectively) were fixed with $2.5 \%(\mathrm{v} / \mathrm{v})$ glutaraldehyde in $0.1 \mathrm{~mol} / \mathrm{ml}$ cacodylate buffer
( $\mathrm{pH}$ 7.4) overnight at $4{ }^{\circ} \mathrm{C}$. The specimens were embedded in Lowicryl $\mathrm{K}_{4} \mathrm{M}$ resin (Polysciences, Warrington, PA, USA). Thin sections were first treated with anti-ZP2 antibody (1:100) and then with a gold-conjugated goat antiserum against rabbit IgG (1:30; E-Y Laboratories, San Mateo, CA, USA). The samples were next stained with uranyl acetate and observed with a model $\mathrm{H}-8000$ electron microscope (Hitachi).

The quantitative evaluation of the labeling density was performed as described previously (Kohsaka et al. 1993). Randomly selected electron micrographs taken at a magnification of $\times 6000-\times 10000$ were enlarged to $\times 19200$ $\times 32$ 000. Each photographic paper $(25 \mathrm{~cm} \times 15.5 \mathrm{~cm})$ was weighed and the surface area of the photographic paper was calculated as $\mu \mathrm{m}^{2} / \mathrm{g}$. The number of the immunogold particles was counted manually, and the areas of the printing paper containing oocytes or granulosa cells were scissored off and weighed. The labeling density was expressed as the number of particles per unit of surface area $\left(\mu \mathrm{m}^{2}\right)$. Data were expressed as means \pm s.D. and were subjected to Student's $t$-test using Excel (Microsoft). Differences were considered statistically significant when $P<0.05$.

\section{Declaration of interest}

The authors declare that there is no conflict of interest that could be perceived as prejudicing the impartiality of the research reported.

\section{Funding}

This work was supported in part by financial assistance from Ito Scientific Foundation (Tokyo, Japan) and Hamamatsu Scientific Foundation (Hamamatsu, Japan) to T Sasanami.

\section{Acknowledgements}

The authors are grateful to Miss Tsukasa Sato and Miss Ayako Katayama for their technical assistance.

\section{References}

Altschul SF, Madden TL, Schaffer AA, Zhang J, Miller W \& Lipman DJ 1997 Gapped BLAST and PSI-BLAST: a new generation of protein database search programs. Nucleic Acids Research 25 3389-3402.

Bausek N, Waclawek M, Schneider WJ \& Wohlrab F 2000 The major chicken egg envelope protein ZP1 is different from ZPB and is synthesized in the liver. Journal of Biological Chemistry 278 28866-28872.

Bellairs R, Harkness M \& Harkness RD 1963 The vitelline membrane of the hen's egg: a chemical and electron microscopical study. Journal of Ultrastructure Research 8 339-359.

Bleil JD \& Wassarman PM 1980 Synthesis of zona pellucida proteins by denuded and follicle-enclosed mouse oocytes during culture in vitro. PNAS 77 1029-1033.

Bork P \& Sander C 1992 A large domain common to sperm receptors (ZP2 and ZP3) and TGF- $\beta$ type III receptor. FEBS Letters 300 237-240.

Conner SJ \& Hughes DC 2003 Analysis of fish ZP1/ZPB homologous genes evidence for both genome duplication and species-specific amplification models of evolution. Reproduction 126 347-352. 
Conner SJ, Lefievre LL, Hughes DC \& Barratt CLR 2005 Cracking the egg: increased complexity in the zona pellucida. Human Reproduction $\mathbf{2 0}$ 1148-1152.

Dean J 2003 Reassessing the molecular biology of sperm-egg recognition with mouse genetics. BioEssays 26 29-38.

Epifano O, Liang L, Familari M, Moos MC \& Dean J 1995 Coordinate expression of the three zona pellucida genes during mouse oogenesis. Development 121 1947-1956.

Ganguly A, Sharma RK \& Gupta SK 2008 Bonnet monkey (Macaca radiata) ovaries, like human oocytes, express four zona pellucida glycoproteins. Molecular Reproduction and Development 75 156-166.

Goudet G, Mugnier S, Callebaut I \& Monget P 2008 Phylogenetic analysis and identification of pseudogenes reveal a progressive loss of zona pellucida genes during evolution of vertebrates. Biology of Reproduction $78796-806$.

Greve JM \& Wassarman PM 1985 Mouse egg extracellular coat is a matrix of interconnected filaments possessing a structural repeat. Journal of Molecular Biology 181 253-264.

Hamazaki T, luchi I \& Yamagami K 1985 A spawning female-specific substance reactive to anti-chorion (egg-envelope) glycoprotein antibody in the teleost, Oryzias latipas. Journal of Experimental Zoology 235 269-279.

Hamazaki TS, Nagahama Y, luchi I \& Yamagami K 1989 A glycoprotein from the liver constitutes the inner layer of the egg envelope (zona pellucida interna) of the fish, Oryzias latipes. Developmental Biology 133 101-110.

Hoodbhoy T, Joshi S, Boja ES, Williams SA, Stanley P \& Dean J 2005 Human sperm do not bind to rat zonae pellucidae despite the presence of four homologous glycoproteins. Journal of Biological Chemistry $\mathbf{2 8 0}$ 12721-12731.

Howarth B 1990 Avian sperm-egg interaction: perivitelline layer possesses receptor activity for spermatozoa. Poultry Science 69 1012-1015.

Hughes DC 2007 ZP genes in avian species illustrate the dynamic evolution of the vertebrate egg envelope. Cytogenetic and Genome Research 117 86-91.

Ito Y, Kihara M, Nakamura E, Yonezawa S \& Yoshizaki N 2003 Vitellogenin transport and yolk formation in the quail ovary. Zoological Science $\mathbf{2 0}$ $717-726$.

Izquierdo-Rico MJ, Jimenez-Movilla M, Llop E, Perez-Oliva AB, Ballesta J, Gutierrez-Gallego R, Jimenez-Cervantes C \& Aviles M 2009 Hamster zona pellucida is formed by four glycoproteins: ZP1, ZP2, ZP3, and ZP4. Journal of Proteome Research 8 926-941.

Kido S \& Doi Y 1988 Separation and properties of the inner and outer layers of the vitelline membrane of hen's eggs. Poultry Science 67 476-486.

Kinoshita M, Mizui K, Ishiguro T, Ohtsuki M, Kansaku N, Ogawa H, Tsukada A, Sato T \& Sasanami T 2008 Incorporation of ZP1 into perivitelline membrane after in vivo treatment with exogenous ZP1 in Japanese quail (Coturnix japonica). FEBS Journal 275 3580-3589.

Kohsaka T, Sasada H \& Masaki J 1993 Subcellular location of the maturation process of relaxin in rat luteal cells during pregnancy as revealed by immunogold labeling. Animal Reproduction Science $\mathbf{3 4}$ 159-166.

Kuroki M \& Mori M 1995 Origin of 33 kDa protein of vitelline membrane of quail egg: immunological studies. Development, Growth and Differentiation 37 545-550.

Laemmli UK 1970 Cleavage of structural proteins during the assembly of the head of bacteriophage T4. Nature 227 680-685.

Lee VH \& Dunbar BS 1993 Developmental expression of the rabbit 55-kDa zona pellucida protein and messenger RNA in ovarian follicles. Developmental Biology 155 371-382.

Lefievre L, Conner SJ, Salpekar A, Olufowobi O, Ashton P, Pavlovic B, Lenton W, Afnan M, Brewis IA \& Monk M 2004 Four zona pellucida glycoproteins are expressed in the human. Human Reproduction 19 1580-1586.

Lindsay LL, Pwavy TR, Lejano RS \& Hedrick JL 2003 Cross-fertilization and structural comparison of egg extracullular matrix glycoproteins from Xenopus laevis and Xeopus tropicalis. Comparative Biochemistry and Physiology, Part A 136 343-352.

Litscher ES \& Wassarman PM 2007 Egg extracellular coat proteins: from fish to mammals. Histology and Histopathology 22 337-347.
Martinez ML, Fontenot GK \& Harris JD 1996 The expression and localization of zona pellucida glycoproteins and mRNA in cynomolgus monkeys (Macaca fascicularis). Journal of Reproduction and Fertility Supplement $\mathbf{5 0}$ 35-41.

Matsudaira P 1987 Sequence from picomole quantities of proteins electroblotted onto polyvinylidene difluoride membranes. Journal of Biological Chemistry 262 10035-10038.

Mcleskey SB, Dowds CR, Carballada R, White RR \& Saling PM 1998 Molecules involved in mammalian sperm-egg interaction. International Review of Cytology 177 57-113.

Menkhorst E \& Selwood L 2008 Vertebrate extracellular preovulatory and postovulatory egg coats. Biology of Reproduction 79 790-797.

Mori M \& Masuda N 1993 Proteins of the vitelline membrane of quail (Coturnix coturnix japonica) eggs. Poultry Science 72 1566-1572.

Nielsen H, Engelbrecht J, Vrunak S \& von Heijne G 1997 Identification of prokaryotic and eukaryotic signal peptides and prediction of their cleavage sites. Protein Engineering 10 1-6.

Ohtsuki M, Hanafy AM, Mori M \& Sasanami T 2004 Involvement of interaction of ZP1 and ZPC in the formation of quail perivitelline membrane. Cell and Tissue Research 318 565-570.

Okumura H, Kohno Y, Iwata Y, Mori H, Aoki N, Sato C, Kitajima K, Nadano D \& Matsuda T 2004 A newly identified zona pellucida glycoprotein, ZPD, and dimeric ZP1 of chicken egg envelope are involved in sperm activation on sperm-egg interaction. Biochemical Journal 384 191-199.

Okumura H, Aoki N, Sato C, Nadano D \& Matsuda T 2007a Heterocomplex formation and cell-surface accumulation of hen's serum zona pellucida B1(ZPB1) with ZPC expressed by a mammalian cell line (Cos-7): a possible initiating step of egg-envelope matrix construction. Biology of Reproduction 76 9-18.

Okumura H, Okajima T, Nadano D \& Matsuda T 2007b Association of chicken zona pellucida glycoprotein (ZP) B1 with ZPC induces formation of ZPB1-ZPC fibrous aggregates containing disulfide-bridged ZPB1 dimer. Biochemical and Biophysical Research Communications 364 682-688.

Pan J, Sasanami T, Kono Y, Matsuda T \& Mori M 2001 Effects of testosterone on production of perivitelline membrane glycoprotein ZPC by granulosa cells of Japanese quail (Coturnix japonica). Biology of Reproduction 64 310-316.

Sanger F, Nicklen S \& Coulson AR 1977 DNA sequencing with chainterminating inhibitors. Biotechnology 24 104-108.

Sasanami T, Pan J, Doi Y, Hisada M, Kohsaka T \& Toriyama M 2002 Secretion of egg envelope protein ZPC after C-terminal proteolytic processing in quail granulosa cells. European Journal of Biochemistry $2692223-2231$.

Sasanami T, Hanafy AM, Toriyama M \& Mori M 2003a Variant of perivitelline membrane glycoprotein ZPC of Japanese quail (Coturnix japonica) lacking its cytoplasmic tail exhibits the retention in the endoplasmic reticulum of Chinese hamster ovary (CHO-K1) cells. Biology of Reproduction 69 1401-1407.

Sasanami T, Pan J \& Mori M 2003b Expression of perivitelline membrane glycoprotein ZP1 in the liver of Japanese quail (Coturnix japonica) after in vivo treatment with diethylstilbestrol. Journal of Steroid Biochemistry and Molecular Biology 84 109-116.

Sasanami T, Toriyama M \& Mori M 2003c Carboxy-terminal proteolytic processing at a consensus furin cleavage site is a prerequisite event for quail ZPC secretion. Biology of Reproduction 68 1613-1619.

Sasanami T, Ohtsuki M, Hanafy AM \& Mori M 2004 Accumulation of ZP1 and ZPC in quail perivitelline membrane during follicular development. Journal of Poultry Science 41 289-293.

Sasanami T, Ohtsuki M, Ishiguro T, Matsushima K, Hiyama G, Kansaku N, Doi Y \& Mori M 2006 Zona pellucida domain of ZPB1 controls specific binding of ZPB1 and ZPC in Japanese quail (Coturnix japonica). Cells, Tissues, Organs 183 41-52.

Sasanami T, Murata T, Ohtsuki M, Matsushima K, Hiyama G, Kansaku N \& Mori M 2007 Induction of sperm acrosome reaction by perivitelline glycoprotein ZP1 in Japanese quail (Coturnix japonica). Reproduction $13341-49$.

Sato T, Kinoshita M, Kansaku N, Tahara K, Tsukada A, Ono H, Yoshimura T, Dohra H \& Sasanami T 2009 Molecular characterization of egg envelope glycoprotein ZPD in the ovary of Japanese quail (Coturnix japonica). Reproduction 137 333-343. 
Smith J, Paton IR, Hughes DC \& Burt DW 2005 Isolation and mapping the chicken zona pellucida genes: an insight into the evolution of orthologous genes in different species. Molecular Reproduction and Development 70 133-145.

Spargo SC \& Hope RM 2003 Evolution and nomenclature of the zona pellucida gene family. Biology of Reproduction 68 358-362.

Takeuchi Y, Nishimura K, Aoki N, Adachi T, Sato C, Kitajima K \& Matsuda T 1999 A 42-kDa glycoprotein from chicken egg-envelope, an avian homolog of the ZPC family glycoproteins in mammalian zona pellucida. European Journal of Biochemistry 260 736-742.

Tanaka M, Yamamoto I, Ohkubo T, Wakita M, Hoshino S \& Nakashima K $1999 \mathrm{cDNA}$ cloning and developmental alterations in gene expression of the two Pit-1/GHF-1 transcription factors in the chicken pituitary. General and Comparative Endocrinology 114 441-448.

Thompson DJ, Higgins DG \& Gibson TJ 1994 CLUSTAL W: improving the sensitivity of progressive multiple sequence alignment through sequence weighting. Nucleic Acids Research 22 4673-4680.

Waclawek M, Foisner R, Nimpf J \& Schneider WJ 1998 The chicken homologue of zona pellucida protein-3 is synthesized by granulosa cells. Biology of Reproduction 59 1230-1239.
Wassarman PM \& Litscher ES 2008 Mammalian fertilization: the egg's multifunctional zona pellucida. International Journal of Developmental Biology 52 665-676.

Wyburn GM, Aitken RNC \& Johnston HS 1965 The ultrastructure of the zona radiata of the ovarian follicle of the domestic fowl. Journal of Anatomy 99 469-484.

Yamaguchi S, Hedrick JL \& Katagiri C 1989 The synthesis and localization of envelope glycoproteins in oocytes of Xenopus laevis using immunocytochemical methods. Development, Growth and Differentiation 31 85-94

Yoshimura T, Suzuki Y, Makino E, Suzuki T, Kuroiwa A, Matsuda Y, Namikawa T \& Ebihara S 2000 Molecular analysis of avian circadian clock genes. Molecular Brain Research 78 207-215.

Received 1 June 2009

First decision 6 July 2009

Revised manuscript received 7 October 2009

Accepted 21 October 2009 